Post-Print de: Journal Of Destination Marketing \& Management, 18, 100499. https://doi.org/10.1016/j.jdmm.2020.100499

\title{
The social value of heritage: Balancing the promotion-preservation relationship in the Altamira World Heritage Site, Spain
}

\author{
Eva Parga-Dans (IPNA-CSIC) \\ Pablo Alonso González (IPNA-CSIC) \\ Raimundo Otero Enríquez (Universidade da Coruña)
}

\begin{abstract}
The designation of World Heritage Sites (WHSs) by UNESCO strengthens the international and national image of heritage destinations in the growing market of cultural tourism. Understanding how different stakeholders interpret the value of cultural heritage is one of the most important assets for balancing the promotion and protection of WHSs. This study draws on the case of the Altamira Prehistoric Cave WHS (Spain), whose preservation is under threat and constant debate. It explores factors determining the social value of heritage, namely: existence, aesthetic, economic, and legacy value. In doing so, this paper contributes to emerging debates on heritage management and tourist destinations. Data were collected using two surveys, one focused on visitors, with a total of 1047 valid surveys, and another on the Spanish population as a WHS host community, with a total of 1000 valid surveys. The analysis of these surveys shows how the existence, aesthetic, economic and legacy value dimensions of cultural heritage can build up brands around WHSs. The social-value dimension of cultural heritage therefore affects the market potential of WHSs, whose market potential is closely related to the education levels of a given society. These findings provide valuable information and insights for academics, destination managers and policymakers in the debate about the preservation and tourism branding of Altamira. This will allow different stakeholders to identify opportunities to develop synergies between tourism promotion and heritage preservation, to both strengthen the brand image of a WHS and preserve its heritage.
\end{abstract}




\title{
Keywords
}

\author{
Social value; Altamira world heritage site; Heritage tourism; Heritage \\ preservation; Destination branding; Tourism destination
}

\section{Introduction}

Cultural tourism, and more specifically heritage tourism, is recognized as the largest and fastest-growing global tourism market (Timothy \& Boyd, 2006). According to the World Tourism Organization (2018), four out of ten tourists choose their destination according to its cultural attractions. Based on this growing trend, a report by the World Tourism Organization estimates that the annual growth rate in cultural trips will be $15 \%$ by the end of the century. Specifically, this report highlights heritage as the key asset for cultural tourism development, and European countries as important destinations due to their abundant surviving cultural heritage. In parallel, the European Union designated 2018 as the European Year of Cultural Heritage, emphasizing the need for a specific policy agenda regarding heritage management. This has provided a great opportunity to promote synergies between heritage, culture and tourism. This paper examines the impact of the social value ascribed to World Heritage Site designations impact on the management and promotion of destination brands. Social sciences such as history, archaeology, anthropology, sociology, and more recently marketing and management, have already largely explored the complex relationship between heritage protection and tourism promotion from multiple points of view (Apostolakis, 2003; Timothy, 2018). However, no study has as yet looked at such issues connecting a social value perspective with destination branding, with the added value of focusing on such a unique WHS as Altamira.

Overall, such investigations share a concern about the inherent value of cultural heritage assets as key potential tourism resources, and as such, a factor for local development (Ramires et al., 2018). Heritage destinations have to manage the dimensions of their touristic development. They must find a balance between the promotion of tourism and economic growth on the one hand, and the preservation of artefacts, historical sites, and local traditions on the other (Poria et al., 2003). Heritage destinations must therefore face their own specific challenges in that they generally present various stakeholders, limited economic and management resources, and lack of local identities (Morgan \& Pritchard, 2006). The difficult equilibrium between promoting tourism and preserving heritage acquires increased significance when considering UNESCO WHSs, especially those such as Altamira whose remains (particularly cavepaintings) are highly delicate and perishable (Tucker \& Carnegie, 2014). It has been argued that WHS designations work similarly to a brand (Ryan \& Silvanto, 2010), which can shed light on how social value conditions and influences both management policies and political decisions about specific sites. The WHS declaration implies an acknowledgement of the outstanding universal value of a site as a brand that guarantees its quality, authenticity and pricelessness, increasing the interest of potential tourists (Michelson \& Paadam, 2016). This also generates a need to design and implement conservation policies to manage the impacts of tourism and assure its integration into local economic activities and resident communities (Ramires et al., 2018).

WHSs are designated following the World Heritage Convention guidelines (UNESCO, 1972), based on expert-driven assessments of aspects such as their historical, architectural, environmental, human and cultural importance, as well as the degree of deterioration, physical integrity, and authenticity (Bertacchini et al., 2017; Poria, Reichel, \& Cohen, 2013). However, these expert-driven criteria that determine the outstanding universal value of WHSs may not be interpreted in the same way by other 
interested parties, such as visitors or residents. This generates disagreements over site management and leads to controversies and tensions centred particularly around the preservation-promotion dichotomy (Parkinson et al., 2016). Moreover, research is contradictory regarding the potential and impact of WHSs regarding tourism and brand building: some argue that the benefits of WHS designation are overstated (Hall \& Piggin, 2002), while others confirm its importance as a tourism attractor (Carter, Jolliffe, \& Baum, 2001). There is also a need to incorporate different stakeholders' perspectives into the heritage tourism-preservation dilemma. Consequently, several studies have focused on non-expert positions such as the impressions and opinions of visitors, residents or host communities regarding WHSs (Bourdeau \& Gravari-Barbas, 2016; Conway, 2014). More specifically, some authors explore the concept of authenticity as a factor that influences the visitor's perception of a WHS (Baral, Hazen, \& Thapa, 2017; $\mathrm{Fu}, 2019)$, or visitor experience quality and satisfaction (Chen \& Chen, 2010). Others even criticize the notion of 'universal value' as a core principle of World Heritage (Tucker \& Carnegie, 2014).

However, most studies neglect the role of social value in promoting the brand image of WHS and attracting tourism. In doing so, they overlook a key building block contributing to the allure of heritage sites, which differ from other tourism sites by their added value components such as aesthetics, cultural legacies, and historical aspects. These elements also play a fundamental role in the promotionpreservation dichotomy haunting most heritage sites. The aim of this paper, therefore, is to characterize the social-value dimension of cultural heritage in relation with the brand image of WHSs. It asks whether the WHS brand serves as a substitute for missing knowledge (Petr, 2009), or, on the contrary, the more knowledge and information a society possesses, the easier it is to build a brand for a heritage site. The originality of this paper rests on the characterization and use of social value as an analytical category regarding WHSs destination branding focusing on visitors and residents. This expands the range of nonexpert stakeholders considered when examining decision making in heritage management, an issue seldom explored as denounced by the field of Critical Heritage Studies (Alonso González, 2018). The rationale is to move beyond the expert assessments and positions that tend to dominate heritage management and preclude a deeper understanding of brand image construction (Smith, 2006). Examining how key interested agents, namely visitors and residents, interpret the social value of cultural heritage provides key insights to understand the precarious balance between promotion and preservation of WHSs. In doing so, this paper seeks to explore how social value can contribute to strengthening the international and national image of heritage destinations in the growing market of cultural tourism. Empirical evidence is drawn from a case study of Altamira Cave, Spain, declared a UNESCO WHS in 1985. This case study is paradigmatic because of the long-standing controversy between preservationist advocates of closing the cave to visitors and those supporting its reopening to promote tourism and economic growth. This ongoing polemic offers a unique opportunity to explore the social value dimension of cultural heritage regarding the logic of tourist destinations. The results from this research effort advance knowledge in the fields of cultural heritage management, destination branding and heritage tourism, showing the importance of social value as an analytical category and empirical process.

\section{Theoretical background}

The seminal studies of Fowler (2003), Poria et al. (2003), and Timothy and Boyd (2006) showed that heritage tourism has grown from a complex interplay between supply and demand. What counts most is not the given attributes of a heritage site, but rather how residents and visitors perceive them. In this sense, the works of Jones (2017) show how authorized heritage discourses or expert-driven modes of assessing the significance of sites fail to capture the dynamic, iterative, and embodied nature of the social value of heritage. Consequently, it would be necessary to explore the unofficial and informal modes of engagement of different stakeholders. The complex relationship between visitors and local communities is, however, seldom explored: an issue compounded by the fact that the host communities of a WHS can also become potential heritage tourists. This complicates the preservation-promotion dichotomy: while scientists, museums, and professionals tend to be concerned with the preservation function, hospitality and tourism businesses tend to be concerned with promotion and profit-making (Poulios, 2010). This obvious split in priorities leads to political conflict when policymakers need to make decisions regarding the management of sites that alter the preservation-promotion balance. This has resulted in a growing gap 
between scholarly theoretical contributions and practical empirical studies, leading to a lack of useful guidelines regarding WHS and heritage destination branding (Jansen-Verbeke, 2016). Indeed, few multidisciplinary discussions address the lessons learnt from success and failure in the various case studies around the world (Ryan \& Silvanto, 2010). There is a need to explore the values and interests behind WHS management, balancing benefits and costs, and preservation and promotion interests. Such studies should be based on solid empirical knowledge, beyond the supply and demand dichotomy (Saeedi \& Heidarzadeh Hanzaee, 2016). This paper sets out to explore how the notion of social value can play a role in establishing a cross-disciplinary dialogue that bridges the gap between supply and demand perspectives, while facilitating the development of practical guidelines and criteria for policymakers (De la Torre, MacLean, Mason, \& Myers, 2005).

The social dimension of value has a long-standing scholarly tradition within the field of heritage management studies (Marta De la Torre, 2002; Smith, 2009). Many authors recognize the Burra Charter (Icomos Australia, 1999 [1979]) as a key document in considering cultural heritage significance as the sum of the interlocking values of various social groups. These values include aesthetic, historic, or scientific features that are important for past, present and future generations. The latest version of the Charter emphasizes that contemporary communities who attach specific meanings and values to heritage locations should be involved in their conservation and management. Since then, greater realization of the social value of heritage has triggered a heated creative debate between scholars and policymakers, due to the potential implications of WHS management in particular (Araoz, 2011). Thus, the Burra Charter broke with the traditional separation between the intrinsic value of heritage, i.e. its role in the collective memory and identity of society, and its instrumental value, i.e. its potential for socioeconomic development.

More recently, social value has been defined "as a collective attachment to place that embodies meanings and values that are important to a community" (Jones, 2017, p. 22). From this perspective, the collective attachment to heritage is understood as a changing dynamic dimension in regard to different communities across time and space, rather than a fixed value category. Understanding social value as a process requires incorporating a multiple stakeholder perspective (Alonso González, 2014). However, the complexity involved in attempting to consider social value in terms of management, and especially measuring its effectiveness, has involved a shift in the academic debate on cultural heritage from a focus on theory to attempts to put it into practice (Díaz-Andreu, 2017). This involves adopting a pragmatic position whereby social value is understood as a fluid and specific process of valuing cultural heritage by communities. In doing so, it becomes possible to explore value categories such as economy, aesthetics, existence, or identity as sub-products of a process of valuation carried out by communities, instead of taking these categories for granted from the start. Thus, for instance, it is not that aesthetic or economic value are subcategories of social value; rather, communities see these categories as separate and valuable for some reason. Indeed, because some communities will prioritise specific sets of categories, it becomes possible to render analysis of social values useful in practice by offering advice to heritage managers and policymakers based on insights offered by affected communities, instead of implementing policy based on rigid notions developed by experts and global heritage institutions.

In the context of tourism, the 'outstanding value' dimension of UNESCO's WHSs has acquired analytical relevance. For instance, Michelson and Paadam (2016) explore the inter-linkage between the symbolic value of heritage as a social construct and destination branding through observational techniques. Similarly, Chen and Chen (2010) examine the effects of the heritage visitors' experience on their perceived value of touristic services and visitor satisfaction. Another strand of research understands value as a fixed category for exploring the economic impact of heritage, analysing visitor expenditure (Ramires et al., 2018), or its multiplier effect on regional and local GPD (Parga Dans \& Alonso González, 2018). Several investigations point out a series of subcategories to explain the visitors' or a community's attachment (or not) to their local cultural heritage (Alonso González, 2016; Rasoolimanesh et al., 2017).

Anthropologists have also considered the impact of WHSs on local communities' perceptions of heritage and value orientations from qualitative standpoints (Alazaizeh et al., 2016; Su et al., 2016). These studies show conclude that to gain an understanding of social value it is necessary to carry out research with communities of interest using qualitative and quantitative methods derived from sociology and anthropology. These involve the use of various techniques in attempting to consider social value and then measuring its effectiveness (Jones, 2017). The seminal study by Goulding (2000) developed a focused axial coding to explain the constructed nature of heritage authenticity, based on three core drivers of visitors' interests in heritage, namely existence, aesthetic and social. Garrod et al. (2012) explore the 
processes of participation of local communities through a web-based survey and how they influence the management of destinations. Various investigations thus acknowledge the pivotal role of visitors and local communities in the field of WHS's destination branding. More recently, Parga Dans and Alonso González (2019) conceptualized social attachments to WHSs, showing the need to take into account four key values to optimize heritage management strategies and sustainable tourism, namely existence, aesthetic, economic, and legacy value. What remains to be explored, however, is how these categories of social value can contribute to strengthen WHS branding, an issue disregarded both by destination brand literature and heritage management studies. This investigation draws on these approaches and advances knowledge based on a large-scale empirical assessment of heritage values in a controversial WHS such as Altamira in Spain. In doing so, it highlights the relevance of social value analyses in practice, connecting for the first time the realms of heritage management and destination branding.

\subsection{The 'existence' dimension of heritage value}

Cultural heritage is not self-evident, nor does it possess an intrinsic or inherent value (Poulios, 2010). Therefore, as the Burra Charter emphasizes, the sustainable management of heritage sites should start with an understanding of their significance. The acknowledgement of an object or heritage site beyond the academic perspective by various stakeholders can legitimate a social interest in it, according to its 'existence value' (Darvill, 1994) or 'historic value' (Mason \& Avrami, 2002). This justifies the need for a contemporary approach to heritage preservation. For Darvill, "first is the existence of some evidence, record or memory of things we are trying to draw upon, and second our ability to attribute meaning to what we have. Such meanings are not necessarily right or wrong, they are attributed as part of the process of recognition, derivation, and renegotiation into a future state" $(1994, \mathrm{p}$. 55). This strand of research was taken up by Goulding (2000), who associates the notion of 'existence visitor' with those who search for contemporary touristic experiences through material culture, heritage and objects from the past. In this line, Parga Dans and Alonso González (2019) argue that existence value primarily refers to a contemporary function of heritage. This paper goes beyond this stance to show that existence value can be explored statistically because it coincides with the pre-travel expectations held by visitors. Thus, the existence value of heritage refers to the perceptions, expectations and knowledge about a specific site held by a specific (non-expert) stakeholder group, including local communities and visitors. This confers on heritage sites an existence value that makes them attractive; they thus function as 'heritage brands', opening the door to their management as destinations.

\subsection{The 'aesthetic' dimension of heritage value}

Only when the existence value of heritage has been acknowledged does it become possible to characterize its aesthetic value. The aesthetic dimension of heritage has been widely recognized and researched, and refers to the attachment of sensory perceptions to a heritage site by different stakeholder groups in the present (Icomos Australia, 1999 [1979]). In the field of tourism studies, it is associated with a symbolic function of the past in the present. In this sense, Goulding (2000) argues that the aesthetic dimension of value describes perceptions of the past through a contemporary lens regarding the arts, architecture and craftsmanship, with the consequent idealization of previous eras. Finally, the aesthetic dimension has been analysed as a factor that strengthens the perceived authenticity (Viu et al., 2008) and destination loyalty (Fu, 2019) of a WHS.

\subsection{The 'economic' dimension of heritage value}

The economic value of heritage is widely acknowledged as a key positive quality but has also been understood as a problematic challenge in regard to conservation planning for heritage sites (Mason \& Avrami, 2002). In the field of heritage management studies, economic value is considered a key feature, especially its use as a resource for the generation of wealth (Parga Dans \& Alonso González, 2018). Every heritage site is potentially an asset in the economic sense: it requires investment to acquire and maintain it, yielding a flow of income. Some of these benefits can be traced to markets and can therefore be expressed as prices and income (Mason \& Avrami, 2002). Therefore, the economic dimension of heritage can be analysed through studying the perceptions held by different social groups (Darvill, 1994). Following Chen and Chen (2010), the economic dimension of value is related to the overall assessment of services provided to tourists and how much they spend on them. Instead, we understand the economic value of heritage in terms of the economic impact the heritage site has on the surrounding territory, and in 
terms of its long-term sustainability. Ultimately, the economic dimension of value deals with quantitative factors regarding overall expenditure on heritage sites and its economic impact on the territory.

\subsection{The 'legacy' dimension of heritage value}

Once cultural heritage has an existence value (it is recognized as such) and an aesthetic or artistic value (it causes sensory or symbolic perceptions of the past in the present), and is considered a resource (generates monetary spending, expense or income), it is likely that conflicts will arise over aspects related to the promotion-preservation dichotomy (Graham et al., 2016). Legacy value refers to the need to balance the promotion-preservation dichotomy of cultural heritage and its management aspects in the present and future (Parga Dans \& Alonso González, 2019). Mason and Avrami (2002) draw attention to the fact that heritage conservation is an observable practice in all cultures and at all times. For them, preserving objects and places from the past is vital in the functioning of any society, it represents a capacity for storytelling and preserving the legacy of past societies and traditions. This enduring potential contributes to understanding of how human and social evolution speaks to the future. The legacy value thus refers to the future dimension of the past, or what is decided as worth preserving as an inheritance for future generations (Mason \& Avrami, 2002). It is embedded in stakeholders' perceptions of heritage conservation and management plans, as well as the promotion of tourism, and includes all aspects related to the controversy about site management between the different interested parties. Branding and communication strategies are also involved (Michelson \& Paadam, 2016), along with normative issues such as who should have the authority to make decisions regarding conservation and heritage management, and for whom (ICOMOS, 2019).

\section{Methodology}

One key problem in this research field is the lack of consensus regarding the measurement instruments better suited to analyse the social value of heritage. As previously seen, former studies have set out theoretical understandings of social value based on qualitative methodologies underpinned by ethnographic and survey data. This paper goes beyond the state of the art by developing an original analytical model for measuring the social value of heritage. Its results can be potentially replicated in other heritage sites throughout the world. To guarantee the validity of the study, two surveys were launched based on an ambitious sample design sustained by 2045valid questionnaires. Empirical evidence draws from the Altamira Prehistoric Cave WHS (Spain) and incorporates a quantitative analysis to different stakeholders involved: (1) a representative sample of the Spanish population as the WHS host community, comparing the results with a further sample of the region that hosts Altamira (Cantabria); and (2) a representative sample of visitors. Moreover, to double-check the validity of the study, a categorical principal component analysis (CATPCA) and an analysis of variance (ANOVA) were employed to determine the social value of Altamira WHS. Both statistical methodologies have been successfully employed in other WHSs by Lourenço-Gomes, Rebelo, \& Ribeiro (2019) and Santa-Cruz \& LópezGuzmán (2017) without a specific focus on social value. The reliability of the study is ensured by the statistical significance of the variables employed to measure the social value of heritage. Specifically, the CATPCA analyses show the significant correspondences, taking into account the value of $\chi^{2}$ and the significance level of the test $(\mathrm{p}<.01$ or $\mathrm{p}<.05)$. In turn, for each ANOVA performed, the contrasts of means are statistically significant $(\mathrm{p}<.01)$. Moreover, the statistical assumptions of homoscedasticity and normality are evaluated following Levene-Brown statistics to discard the equality of variances, along with a post-hoc Games-Howell test and a Kolmogorov-Smirnov test (Hair et al., 2010).

\subsection{The importance of altamira WHS and its outstanding value}

Altamira WHS is located in the Cantabria region of northern Spain. The Altamira complex comprises a museum, the cave itself which preserves some of the world's oldest Upper Palaeolithic rock paintings $(18,500 \mathrm{BC})$, and a full-scale reproduction of the cave: the Neo-Cave. The site has become a major tourist destination since its fortuitous discovery in 1868, attracting a significant number of visitors to Cantabria. In the 1970s, Altamira Cave attracted more than 150,900 visitors per year (see Fig. 1). By 1985, when UNESCO declared this site a WHS, Altamira was already positioned as a worldwide tourist destination. The declaration, however, deepened the tension between the various stakeholders concerning the complex balance between the promotion-preservation interests of the site. The threat to conservation of the cave was real, and the effects of human presence on the paintings generated a great deal of concern among 
various stakeholders, pitting scientists and public authorities against the local community and tourist industry (Saiz-Jimenez et al., 2011).

In fact, the cave had already been temporarily closed to visits on several occasions, first in 1977 after scientists warned about raised CO2 levels. Altamira was reopened in 1982 with a quota that limited access to 11,300 visitors each year, resulting in a waiting list of up to three years (Saiz-Jimenez et al., 2011). The cave was again temporarily closed to the public in 2002 due to the appearance of a green mould on the paintings, similar to that found in Lascaux Cave, in France. Altamira Museum and the 'Neo-cave' were opened in 2001 to assuage the polemic and add detailed background knowledge and value to the cave and its interpretation, allowing visitors an alternative form of access to the heritage experience. In fact, the opening of the Neo-Cave and Museum in 2001 consolidated the importance of Altamira as a cultural centre. An average of 250,000 annual visits was soon reached, surpassing the historical figure of 174,000 visits to the original cave recorded in 1973 (see Fig. 1). Since then, the Altamira WHS has become the second most visited public museum in Spain and a key tourist attractor to Cantabria and to Spain (LPPM, 2010).

The opening-closing dichotomy in Altamira is, however, still ongoing among key stakeholders. In 2014, the cave was again reopened to the public under a strict system of experimental visits that continues to this day. The system of experimental visits consists of groups of five visitors, selected randomly. Visitors can enter the cave each week observing strict attire protocol, in order to continue compiling data about the impact of human presence on the cave. This situation has led to a permanent public debate that ultimately concerns who should have the last word on decisions about the balance between the promotion or preservation of Altamira WHS. The importance of the notion of social value is highlighted in this context, since a further understanding of the values held by different stakeholders can also support policymakers' decisions, beyond the appeal of immediate economic gain and the pressures of pro-conservation scientists.

\subsection{Data collection}

Data were collected using two different questionnaire surveys, one aimed at Altamira visitors and the other aimed at the Spanish population broadly as host community of the WHS. First, the visitor survey consisted of a total of 35 main questions structured from multiple-choice sub-questions distributed in five thematic blocks. The aim was to characterize the social value of Altamira WHS through identifying the building bricks of social value: (i) existence (pre-travel expectations and motivations); (ii) aesthetic (sensory-artistic impact of the destination, its assessment and satisfaction derived); (iii) economic (trip information and visitor spending); (iv) legacy (opinions, attitudes, and behaviors of visitors regarding the promotion-preservation of Altamira); and (v) socio-demographic profile. The questionnaire was administered through a direct approach by a team of interviewers, using a convenience sample of national and international visitors over 18 years old. For this purpose, a simple random sample was designed by taking into account the total number of visitors in 2013, stratified according to age and gender quotas (with a 95\% confidence level and an error of 3\%, with $p=q=0.5$ ). A total of 1047 valid surveys were collected at the museum exit. The sampling period included three different tourist seasons ('high', 'medium' and 'low') from mid-June 2013 to mid-February 2014, from Friday to Sunday.

Second, the Spanish population survey consisted of a total of 28 questions regarding four core value blocks: (i) existence (knowledge and visibility of Altamira); (ii) aesthetic (sensory-artistic impact of Altamira); (iii) economic and legacy (evaluations and opinions regarding the debate over opening/closing of the cave itself, and about how and by whom an ideal preservation-promotion model should be financed); and (iv) socio-demographic profile. This questionnaire was administered by telephone, by a team of interviewers directed at a representative sample of the Spanish population over 18 years old. The survey was non-probabilistic and disaggregated into proportional quotas according to the population of the Autonomous Community of Cantabria, where the Altamira museum complex is located, as well as to the seven Nomenclatures of the Statistical Territorial Units of Spain (NUTS) established by the European Union for statistical purposes. These geographical criteria paved the way for assessing whether proximity affects the average and standard deviation of the general results obtained in the survey. A total of 1000 valid surveys were collected from mid-May to mid-September 2014, from Friday to Sunday. 
Stakeholders' perspectives were incorporated as non-expert assessments with a heritage preservation position and allows for establishing inferences from statistically significant results with implications on heritage management and destination branding. This is justified by the need to incorporate different stakeholders' perspectives into the heritage tourism-preservation dilemma. Consequently, this study has focused on non-expert positions such as the impressions and opinions of visitors, residents or host communities regarding WHSs.

\subsection{Data analysis}

The key analytical concepts of both questionnaires were correlated with final geographic (NUTS) and socio-demographic variables (gender, age, educational level, employment situation and type of occupation), to further knowledge about the existence, aesthetic, economic and legacy dimensions of heritage, which build up the notion of social value. The strategy to analyse the existence, aesthetic and legacy values, regardless of the format of the survey used, was selected because most of the variables used are categorical (ordinal or nominal). First, to obtain an overall synthetic view of the relationships between the variables that represent these three 'values' and the socio-demographic and geographic variables, this study is grounded on both simple correspondence analysis and a CATPCA analysis. These techniques optimize the correlation or correspondence between the categories of variables. Moreover, they provide a visual interpretation of these correlations in a perceptual map or dispersion chart, designed in two dimensions or axes based on $\mathrm{x}$ and y coordinates (Greenacre, 2017; Joaristi et al., 2000).

To obtain perceptual maps a double entry system graphs is performed. These graphs represent the sociodemographic and geographical variables in relation to contrast variables referring to each of the values analysed. They show the significant correspondences, taking into account the value of $\chi 2$ and the significance level of the test $(\mathrm{p}<.01$ or $\mathrm{p}<.05)$. In this way, the total inertia or percentage of variance explained in the first dimension of the perceptual map and the overall meaning of the relationships between categories of variables is displayed (Joaristi \& Lizasoain Hernández, 2000). In the second phase, an analysis of variance (ANOVA) is performed to illustrate the potential of the Altamira complex to transmit its legacy value to its visitors, taking advantage of scale variables to measure the levels of visitor satisfaction. ANOVA is a technique frequently applied in heritage studies (McKercher et al., 2005; Ramires et al., 2018; Wu et al., 2015), to compare several groups or categories of a factor or independent variable with a quantitative scale variable or dependent variable (Hair et al., 2010).

Specifically, this study aimed to contrast in what way the average satisfaction ratings of a visit to Altamira Museum and Neo-Cave (scale variables) are statistically different, depending on the categories of two independent variables that represent legacy value. The first refers to the degree of acceptance of closing the cave to maintain its future conservation, the second illustrates the educational capacity of the museum to explain why the cave is closed. This overall evaluation of the satisfaction generated by the visit to the Altamira museum (and especially to the Neo-cave) is unprecedented. To date, no evaluation of the success of the Neo-Cave in the eyes of visitors had been carried out. Finally, the analyses that determine the economic value are a synthesis of the economic benefits accrued from descriptive variables about the average duration and expenditure of visits to the Altamira museum. The raw data using in this research were previously used to carry out a study that successfully estimated the direct economic impact of this WHS (Parga Dans \& Alonso González, 2018).

\section{Results and discussion}

\subsection{The 'existence' dimension of social value}

In addition to the tourist appeal of Altamira, its contemporary significance for the Spanish population underlines its existence value. Eighty-three percent of the Spanish population knew of the existence of Altamira. Therefore, there is widespread social recognition of this heritage site, attributing it a value of 'existence' and a power to attract tourists (Poulios, 2010). The scope of its 'existence value' in Spain can be defined more precisely by gauging the level of knowledge that Altamira exists and taking into account socio-demographic variables. Although the majority of the Spanish population were aware of its existence, a sociodemographic profile with greater knowledge about the museum complex was segmented. It included people aged between 40 and 64 years old (87.9\%), with university studies $(94.6 \%)$ and occupations related to education, arts, culture or research $(95.0 \%)$ 
Analysis of the sociodemographic segmentation variables shows that educational level significantly discriminates the highest and lowest levels of knowledge about the existence of Altamira $(\chi 2=123.087, p$ $<.01)$. Specifically, compared to the $94.6 \%$ reached by the population with university education, it was the less educated people who made up the lowest percentage who had heard of the cave (62.1\%). Thus, a higher education level implies a higher existence value accrued to the site, which counters Petr's (2009) argument about the WHS brand serving as a substitute for missing knowledge. In the case of Altamira WHS, the more knowledge and information people had of it, the easier it was for them to connect with the existence value of heritage, and therefore to develop a brand from a heritage site.

Isolating the Cantabrian Autonomous Community from the remaining Spanish NUTS, Altamira's existence value is illustrated from a territorial perspective (Fig. 2). With the exception of the Canary Islands NUT, the population of other geographical units affirm that they know of the existence of Altamira in percentages above $75 \%$. Further examining these high percentages, the Autonomous Community of Cantabria and NUTS Central Peninsula and Community of Madrid show percentages higher than $90 \%$. Therefore, geographical proximity to the Altamira Complex plays an important role in its recognition and explains that the correspondence between the variables is significant $(\chi 2=36.174$; $\mathrm{p}<$ $.01)$.

The CATPCA provides a spatial representation of the joint behaviour of the segmentation and contrast variables, i.e. knowing that Altamira Cave exists. The visualization of the first spatial dimension shows that the population segments whose coordinates or centroids were close to the category 'never heard of Altamira' were the population over 65 years old, mostly a population without secondary or primary studies, and residents of the Canary Islands. In contrast, a large number of socio-demographic characteristics and geographical areas of Spain cluster around the 'yes I know about it' (proving, in this way, the strength of Altamira's existence value)

The visitors' knowledge about the existence of Altamira can be taken for granted since they are already on-site. Even so, some results provide information about this dimension of value. For instance, $83.3 \%$ of them stated that Altamira is a fundamental place for understanding or seeking information about the prehistory of humanity, even without access to the original cave and paintings. It is therefore possible to confirm the existence value attached to Altamira in the present by visitors and the host community, independently of their sociodemographic profile or territorial proximity. This contributes to the overall contemporary social value of this WHS. Beyond this generality, geographical proximity to the museum complex and educational level play a decisive role in its recognition. Acknowledgement of this existence value by social groups such as visitors and the Spanish population, in addition to its public status as a WHS established by expert stakeholders, is an argument in favour of focusing on this site in regard to the protection-promotion dichotomy.

More specifically, various studies have shown that World Heritage tourism is a key opportunity to increase the visibility and demand for a destination among heritage global market niches (Adie et al., 2017; Ramires et al., 2018). This study demonstrates the inverse of previous studies: Altamira is a place that attracts Spanish population $(86 \%)$ to a greater extent that it does international tourist interest.

Indeed, the existence value can be a determining factor to reinforce the image of a WHS among a host community that can also become tourists, reinforcing in turn its existence value. In light of the lack of research in this regard, the present study identifies potential non-expert stakeholder attachments to a WHS.

\subsection{The 'aesthetic' dimension of social value}

The perceptions of Altamira were based on historical associations with the arts, architecture and craftsmanship. This shows the strong correlation with the perception of authenticity in the site, and underpins its aesthetic value, confirming the findings of Goulding (2000) and Parga Dans and Alonso González (2019) in this regard. Survey results illustrate that more than $70 \%$ of the Spanish population considered that the most important element of Altamira as a heritage site is its rock paintings, compared to other reasons such as it being declared a WHS (4.7\%). The others were that it is a destination of tourist interest $(1.5 \%)$, or a symbol and mark of regional identity $(1.5 \%)$. Therefore, in addition to a common contemporary recognition of the Altamira WHS by foreign visitors and the Spanish population, there is also an ongoing process of attribution of meanings to this heritage site, among these an aesthetic value. 
As was the case with their existence value, recognition of the aesthetic value of the prehistoric paintings by the Spanish population who knew of Altamira was very high in all regions/NUTS (higher than $68 \%$ in all cases). With the exception of Cantabria (in which $44.8 \%$ of its population understood that Altamira has multiple claims of interest), the figures for the recognition of this value in the Spanish NUTS did not show great geographical disparities. This is the reason why the correspondence between these two variables was not significant $(\chi 2=14.012, \mathrm{p}>.05)$.

Agreement on the importance of the paintings (with respect to any other consideration) exceeded $50 \%$ of the answers given in any case. In contrast, 'for being a WHS' as a key element of Altamira held a much lower proportion of consensus in all response categories. Indeed, except for students, this variable did not exceed $10 \%$ of the total.

The CATPCA between the segmentation and contrast variables (i.e. why Altamira is important) discriminates firstly a double profile that clearly accepts and appreciates the aesthetic impact of the Altamira paintings in Spain. This represents mainly workers with university studies or baccalaureatevocational training students. It stands in clear contrast with another profile where the importance of Altamira was felt with less intensity, including retired, generally older people, and those 'without studies' (including those who did not went to school and those who did not finished primary studies) or with primary educational levels.

The findings after addressing the visitors' aesthetic perceptions highlight the connection between the public appreciation of Altamira and its prehistoric paintings. As with its existence value, it is educational level that determines the aesthetic value of Altamira: the more knowledge and information society possesses, the easier it is to connect the aesthetic value of Altamira's paintings as a heritage brand beyond its designation as WHS. Therefore, at an empirical level, the Altamira experience shows the relative importance of the brand image of a WHS designation, at least in its aesthetic dimension of value. The results of this study show that Altamira's declaration as a WHS is not a factor that holds relevance for either visitors or the local host community in their perception of the place, or at least it is very far from the importance they attribute to the paintings. This is true regardless of the sociodemographic profile and geographical proximity of both its visitors and host community. Moreover, the results show a highly notable average satisfaction level after the visit: 5.9 average points on a scale of $1-$ to 7 . The Neo-Cave is thus not diminishing the aesthetic value of Altamira. This is especially the case among the public that has a clearer understanding of the artistic importance of Altamira's paintings, despite not being able to see the originals. The results therefore relativize the outstanding universal value established by panels of experts, in convergence with the study by Tucker and Carnegie (2014). In fact, through understanding the factors that discriminate the aesthetic values or biases of non-expert stakeholders, it is possible to gauge the social appraisal of this WHS and the underlying factors behind its attraction as a tourist destination and cultural brand.

\subsection{The 'economic' dimension of social value}

The social value of Altamira is associated with its economic value. The results of this investigation show that the Altamira Complex is able to attract a significant number of visitors and is a determining factor in visitors' decisions to choose the region of Cantabria as a tourist destination. The results of the survey highlight the potential of attraction held by Altamira, which was the single most determining factor in the trip for almost $40 \%$, while for the remaining $60 \%$ it was a very important factor. Eighty-four percent of visitors affirmed having organized their trip without any expectation of visiting the original cave. Of those, $71 \%$ expected to encounter a good replica of it in the Neo-Cave. Specifically, the average length of stay was 4.6 nights in the region, which represents, on average, about $26 \%$ of the travellers staying in accommodation establishments in Cantabria (INE, 2013). Their accommodation- and food-related costs accounted for most $(63 \%)$ of the total expenditure. In turn, expenses related to leisure, culture and entertainment made up $11 \%$. The average expenditure per capita and per day was $€ 104.50$. These data were used to estimate the direct economic impact of the Altamira WHS, which involved a total of $€ 113$ million on the region of Cantabria, $8.5 \%$ of the overall tourism GPD for Cantabria and $0.9 \%$ of the region's total GDP (Parga Dans \& Alonso González, 2018). Thus, visitor spending greatly benefits the regional economy. 
Altamira WHS therefore has, or generates, a significant economic value through this expenditure, with a substantial positive economic impact on the territory. The present research was concerned with the value associated with the sociocultural significance of this heritage site, which generates an important source of income for the inhabitants of the region. Their main interest has become the need to ensure the long-term conservation of the Cave as well as the ongoing promotion of visits to the site. In this sense, Altamira conforms a 'cultural imaginary' as well as an 'operant resource' for the commodification of this archaeological site, with socioeconomic implications for the local community, following the terminology used by Ross et al. (2017).

\subsection{The 'legacy' dimension of social value}

Perceptions among visitors as well as the Spanish population regarding the legacy dimension show that Altamira Cave is a heritage asset to be preserved for future generations, beyond any potential scenario for its reopening. First, of the total population that knew the cave exists (83\% of the Spanish population), $81.2 \%$ also knew it was closed to the public. Other aspects demonstrate the importance that the Spanish population attributes to the legacy value. Most people, up to $92.2 \%$ of respondents, accepted that the Cave remains closed to guarantee its future conservation. Secondly, a majority $(55.3 \%)$ also accepted that its future conservation remains the financial responsibility of all Spaniards, through the tax system. Knowledge of the Cave's closure to the public is general in all the Spanish NUTS and the province of Cantabria, with percentages of affirmative answers higher than $87 \%$. In the case of the legacy value, territorial disparities were not significant enough to alter this high degree of consensus. It is therefore necessary to consider the importance of the heritage value of Altamira WHS independently of the region of residence.

In addition, there was a clear consensus among the surveyed populations about the need to implement conservation measures to favour the sustainability and future management of Altamira Cave. A significant majority either understood that the Cave should be opened to 'a limited number of people' $(68.9 \%)$ or accepted that it must be 'closed to the public' $(17.4 \%)$. Deepening the segmentation variables, by far the greatest consensus was found in the 'protectionist' attitudes about the future of the cave ('closed'/'open with limits'). One variable stood out in this regard: the educational level (level of studies) showed a significant correspondence with the question posed. It therefore explains the wide polarity of opinions on how to preserve the 'legacy value' $(\chi 2=28.692 ; \mathrm{p}<.01)$. As with the existence and aesthetic values, it is educational level that allowed a statement of opinion on the legacy value of the Altamira WHS.

Examining this latter observation by means of a simple correspondence analysis, the importance of interviewees' educational level is again seen, on assessing the strength of the legacy value. This means that the higher 'protectionist intensity' defended by respondents correlates with a higher level of education. This is evident in the dispersion graph, in the spatial proximity between the opinion of keeping Thus, the acceptance of the cave's closure to preserve its legacy for the future was also very high among the visiting population. Indeed, $63.8 \%$ of the visitor respondents rated this option as 'very good', and $31.8 \%$ as 'good'. It is important to emphasize that most visitors who support closing the cave are also those most satisfied with the Neo-Cave and the visit to the museum. A further analytical verification through ANOVA demonstrates the relative strength of the legacy value among the visitors. For a large majority, Cave closure does not diminish the degree of satisfaction with the museum complex of Altamira; on the contrary, it increases satisfaction and makes the complex a unique tourism product. Altamira 'closed' and the population with 'university or higher' studies.

Concerning this latest evidence, it should be noted that the Altamira Museum is very effective in reinforcing 'legacy value' as a key teaching-learning experience. In fact, after visiting it, 56.0\% and $24.5 \%$ of its visitors, respectively, understood 'a lot' or 'quite a bit' why the Cave was closed. Moreover, after completing a new ANOVA, results showed how most of those that understood the reasons for closure had significantly higher average satisfaction scores than the minority that did not. 
Study of the legacy value allows to understand the different interpretations of the promotion-protection dilemma from non-expert perspectives including local community and visitors in the case of Altamira, bringing novel insights to the historical debate about its reopening or closing in the future. The main conclusion from this analysis is that educational level was the sociodemographic variable that gave rise to the greatest polarity of opinions on how to maintain the legacy value. Indeed, higher educational levels were linked to greater satisfaction, which again highlights their relevance to the understanding of cultural heritage, its preservation and its interplay with tourism promotion measures. The legacy value associated with a specific heritage site plays a decisive role in implementing conservation policies and proper management of the destination brand. It also promotes the integration of tourism with local economic activities and residents. Finally, as established by Craik (1997), educational level is a key factor in overcoming the attitude that treats cultural tourism as just a convenient marketing strategy. It focuses instead on creating a culture of tourism that understands heritage sites as a new category in the sector, based on the social value of heritage, as discussed here.

\section{Conclusion}

This paper has reported the first investigation addressing the relationship between the social value of heritage and the brand image of the WHS designation in Spain. The study was based on a robust quantitative approach supported by 2047 surveys to a representative sample of the Spanish population (as the WHS host community) and visitors as non-expert interested stakeholders. This thorough analysis has offered a social value perspective that advances knowledge of tourism brand destinations and heritage management by exploring the promotion-preservation dichotomy in the case of the Altamira WHS (Spain). The existence, aesthetic, economic and legacy value dimensions of cultural heritage can build up brands around WHSs, which in turn makes their market potential closely dependent upon the knowledge and education levels of a given society. That is, the more knowledge and information a society acquires, the easier it is for it to construct a heritage site brand. Thus, despite the barriers to establishing clear interrelationships between the empirical evidence for the four values analysed, it is clear that the survey variable 'educational level' corresponds clearly with the values of existence, legacy and aesthetics. The social value of Altamira was closely linked to a cascade of inferences based on educational level. First, the higher the academic level, the more their knowledge of Altamira among visitors and local population. Importantly, the knowledge and valuation of Altamira was higher among younger visitors and the host population, which counters the commonplace assumption about Altamira being a nationalist reference for the Spanish older generation in association with its promotion as a national symbol during the dictatorship of Francisco Franco, ending in 1975. Second, the more knowledge respondents have about Altamira, the more they favour preserving the $\mathrm{c}=\mathrm{Cave}$. Third, the highest aesthetic value was intrinsically related to more education and knowledge about the Altamira rock paintings. Finally, and more importantly for normative purposes in terms of heritage management and sustainability, the greater the educational level and knowledge about the cave, the higher was the level of satisfaction with the visit.

These conclusions contribute novel insights to a long-standing debate in the field of heritage studies, namely the importance of understanding heritage as a social construction rather than as a given fixed feature, whether tangible or intangible. The practical implication of this theoretical insight is that emphasis should be placed on education and training processes when building a brand image of heritage, rather than on short-term marketing and image-building strategies in isolation. This is important, given that the results show that the Altamira WHS generates significant financial value in the form of visitor expenditure, with an immense economic impact on the surrounding territory. This is always conditional on the preservation of the cave, showing how education at all levels is vital for sustainability purposes and to reach a balance in the promotion-preservation dichotomy haunting heritage sites, and their conflictive nature in other senses. Future research should further explore the question of how geographical proximity to WHSs influences or conditions how the social value of heritage functions. In the case of Altamira, proximity plays an important role in its recognition and social attachment; it 
provides a strategic opportunity to reinforce the image of a WHS among a host community, who can also become visitors or tourists. These results provide valuable information for academics, destination managers, and policymakers in decision-making regarding the promotion-preservation dichotomy and tourism branding of WHSs globally.

Funding

This work was supported by MICINN research projects [HAR2013-47889-C3-3-P], [CSO2017-85188-R] and Ramón \& Cajal Programme [RYC2018-024025-I]. Data come from the Project on the Social Value of Altamira, led by the Incipit-CSIC, within the framework of the Research Programme for the Preventive Conservation and Access Regime for the Cave of Altamira (2012-2014), funded by the Spanish Ministry of Education, Culture and Sports. This manuscript has been edited by Guido Jones, currently funded by the Cabildo de Tenerife, under the TFinnova Programme supported by MEDI and FDCAN funds.

CRediT authorship contribution statement

Eva Parga-Dans: Investigation, Supervision, Writing - original draft, Resources. Pablo Alonso González: Visualization, Validation, Conceptualization, Writing - review \& editing. Raimundo Otero Enríquez: Data curation, Methodology, Validation, Formal analysis.

Declaration of competing interest

None.

\section{References}

Adie, B. A., Hall, C. M., \& Prayag, G. (2017). World heritage as a placebo brand: A comparative analysis of three sites and marketing implications. Journal of Sustainable Tourism, 26(3), 399-415.

Alazaizeh, M. M., Hallo, J. C., Backman, S. J., Norman, W. C., \& Vogel, M. A. (2016). Value orientations and heritage tourism management at Petra Archaeological Park, Jordan. Tourism Management, 57, 149-158.

Alonso González, P. (2014). From a given to a construct: Heritage as a commons. Cultural Studies, 28(3), 359-390.

Alonso González, P. (2016). Heritage and rural gentrification in Spain: The case of Santiago Millas (Spain). International Journal of Heritage Studies, 23(2), 125-140.

Alonso González, P. (2018). The heritage machine: Fetishism and domination in Maragatería (Spain). London: Pluto Press.

Apostolakis, A. (2003). The convergence process in heritage tourism. Annals of Tourism Research, 30(4), 795-812.

Araoz, G. F. (2011). Preserving heritage places under a new paradigm. Journal of Cultural Heritage Management and Sustainable Development, 1(1), 55-60. 
Baral, N., Hazen, H., \& Thapa, B. (2017). Visitor perceptions of World Heritage value at Sagarmatha (Mt. Everest) National Park, Nepal. Journal of Sustainable Tourism, 25 (10), 14941512.

Bertacchini, E., Liuzza, C., \& Meskell, L. (2017). Shifting the balance of power in the UNESCO World Heritage Committee: An empirical assessment. International Journal of Cultural Policy, 23(3), 331-351.

Bourdeau, L., \& Gravari-Barbas, M. (2016). World Heritage, tourism and identity: Inscription and co-production. New York, NY: Routledge.

Carter, L. S., Jolliffe, L., \& Baum, T. (2001). Heritage tourism and World Heritage Sites: The case of Newfoundland. Tourism Recreation Research, 26(1), 113-116.

Chen, C.-F., \& Chen, F.-S. (2010). Experience quality, perceived value, satisfaction and behavioral intentions for heritage tourists. Tourism Management, 31(1), 29.

Conway, F. J. (2014). Local and public heritage at a World Heritage Site. Annals of Tourism Research, 44, 143-155.

Craik, J. (1997). The culture of tourism. In C. Rojek, \& J. Urry (Eds.), Touring cultures (pp. 113-136). London: Routledge.

Darvill, T. (1994). Value systems and the archaeological resource. International Journal of Heritage Studies, 1(1), 52-64.

De la Torre, M. (2002). Assessing the values of cultural heritage: Research report. Los Angeles, CA: Getty Conservation Institute.

De la Torre, M., MacLean, M., Mason, R., \& Myers, D. (2005). Heritage values in site management: Four case studies. Los Angeles, CA: The Getty Conservation Institute.

Díaz-Andreu, M. (2017). Heritage values and the public. Journal of Community Archaeology and Heritage, 4(1), 2-6.

Fowler, P. J. (2003). World Heritage cultural landscapes. Paris: UNESCO. Fu, X. (2019). Existence authenticity and destination loyalty: Evidence from heritage tourists. Journal of Destination Marketing \& Management, 12, 84-94.

Garrod, B., Fyall, A., Leask, A., \& Reid, E. (2012). Engaging residents as stakeholders of the visitor attraction. Journal of Tourism Management, 33(5), 1159-1173.

Goulding, C. (2000). The commodification of the past, postmodern pastiche, and the search for authentic experiences at contemporary heritage attractions. European Journal of Marketing, 34(7), 835-853.

Graham, B., Ashworth, G., \& Tunbridge, J. (2016). A geography of heritage. New York, NY: Routledge.

Greenacre, M. (2017). Correspondence analysis in practice. New York, NY: Chapman and Hall/CRC. 
Hair, J., Black, W. C., Babin, B. J., \& Anderson, R. (2010). Multivariate data analysis: International version. Upper Saddle River, NJ: Pearson.

ICOMOS. (2019). European quality principles for EU-funded interventions with potential impact upon cultural heritage. Paris: Icomos.

Icomos Australia. (1999). The Burra charter and guidelines to the Burra charter. Canberra:

Icomos. Hall, C. M., \& Piggin, R. (2002). Tourism business knowledge of World Heritage Sites: A New Zealand case study. International Journal of Tourism Research, 4(5), 401-411.

INE. (2013). Hotel occupancy survey for Spain. https://www.ine.es/dynt3/inebase/en/i ndex.htm?type=pcaxis\&file=pcaxis\&path=/t11/e162eoh/a2013.

Jansen-Verbeke, M. (2016). Foreword. In M. D. Alvarez, F. M. Go, \& A. Yuksel (Eds.), Heritage tourism destinations: Preservation, communication and development. Wallingford: CABI.

Joaristi, L., \& Lizasoain Hernandez, ' L. (2000). Analisis ' de correspondencias. Madrid: La Muralla; Hespérides.

Jones, S. (2017). Wrestling with the social value of heritage: Problems, dilemmas and opportunities. Journal of Community Archaeology and Heritage, 4(1), 21-37.

LPPM. (2010). Conociendo a nuestros visitantes. Estudio de públicos en museos del ministerio de cultura. Madrid: Ministerio de Cultura de España.

Lourenço-Gomes, L., Rebelo, J. F., \& Ribeiro, C. (2019). Residents' perceptions of a World Heritage property: A multivariate analysis. Journal of Cultural Heritage Management and Sustainable Development, 9(2), 212-226.

Mason, R., \& Avrami, E. (2002). Heritage values and challenges of conservation planning. In J. Teutonico, \& G. Palumbo (Eds.), Management planning for archaeological sites (pp. 13-26). Los Angeles, CA: Getty Institute Loyola University.

McKercher, B., Ho, P. S. Y., \& du Cros, H. (2005). Relationship between tourism and cultural heritage management: Evidence from Hong Kong. Tourism Management, 26 (4), 539-548.

Michelson, A., \& Paadam, K. (2016). Destination branding and reconstructing symbolic capital of urban heritage: A spatially informed observational analysis in medieval towns. Journal of Destination Marketing \& Management, 5(2), 141-153.

Morgan, N. J., \& Pritchard, A. (2006). Promoting niche tourism destination brands: Case studies of New Zealand and Wales. Journal of Promotion Management, 12(1), 17-33.

Parga Dans, E., \& Alonso González, P. (2018). The Altamira controversy: Assessing the economic impact of a World Heritage Site for planning and tourism management. Journal of Cultural Heritage, 30, 180-189.

Parga Dans, E., \& Alonso González, P. (2019). Sustainable tourism and social value at World Heritage Sites: Towards a conservation plan for Altamira, Spain. Annals of Tourism Research, $74,68-80$. 
Parkinson, A., Scott, M., \& Redmond, D. (2016). Defining "official” built heritage discourses within the Irish planning framework: Insights from conservation planning as social practice. European Planning Studies, 24(2), 277-296.

Petr, C. (2009). Fame is not always a positive asset for heritage equity! Some clues from buying intentions of national tourists. Journal of Travel \& Tourism Marketing, 26(1), 1-18.

Poria, Y., Butler, R., \& Airey, D. (2003). The core of heritage tourism. Annals of Tourism Research, 30(1), 238-254.

Poria, Y., Reichel, A., \& Cohen, R. (2013). Tourists perceptions of World Heritage Site and its designation. Tourism Management, 35, 272-274.

Poulios, I. (2010). Moving beyond a values-based approach to heritage conservation. Conservation and Management of Archaeological Sites, 12(2), 170-185.

Ramires, A., Brandao, F., \& Sousa, A. C. (2018). Motivation-based cluster analysis of international tourists visiting a World Heritage City: The case of Porto, Portugal. Journal of Destination Marketing and Management, 8, 49-60.

Rasoolimanesh, S. M., Jaafar, M., Ahmad, A. G., \& Barghi, R. (2017). Community participation in World Heritage Site conservation and tourism development. Tourism Management, 58, 142153.

Ross, D., Saxena, G., Correia, F., \& Deutz, P. (2017). Archaeological tourism: A creative approach. Annals of Tourism Research, 67, 37-47.

Ryan, J., \& Silvanto, S. (2010). World Heritage Sites: The purposes and politics of destination branding. Journal of Travel \& Tourism Marketing, 27(5), 533-545.

Saeedi, H., \& Heidarzadeh Hanzaee, K. (2016). The effects of heritage image on destination branding: An Iranian perspective. Journal of Heritage Tourism, 13(2), 152-166.

Saiz-Jimenez, C., Cuezva, S., Jurado, V., Fernandez-Cortes, A., Porca, E., Benavente, D., \& Sanchez-Moral, S. (2011). Paleolithic art in peril: Policy and science collide at Altamira Cave. Science, 334(6052), 42-43.

Santa-Cruz, F. G., \& Lopez-Guzm án, T. (2017). Culture, tourism and World Heritage Sites. Tourism Management Perspectives, 24, 111-116.

Smith, L. (2006). Uses of heritage. London: Routledge. Smith, L. (2009). Deference and humility: The social values of the country house. In J. Pendlebury (Ed.), Valuing historic environments (pp. 33-50). London: Routledge.

Su, M. M., Wall, G., \& Xu, K. (2016). Heritage tourism and livelihood sustainability of a resettled rural community: Mount Sanqingshan World Heritage Site, China. Journal of Sustainable Tourism, 24(5), 735-757.

Timothy, D. (2018). Making sense of heritage tourism: Research trends in a maturing field of study. Tourism Management Perspectives, 25, 177-180. 
Timothy, D. J., \& Boyd, S. W. (2006). Heritage tourism in the 21st century: Valued traditions and new perspectives. Journal of Heritage Tourism, 1(1), 1-16.

Tucker, H., \& Carnegie, E. (2014). World heritage and the contradictions of 'universal value'. Annals of Tourism Research, 47, 63-76. UNESCO. (1972). Convention concerning the protection of the world cultural and natural heritage: Adopted by the general conference at its seventeenth session. Paris: Unesco.

Viu, J. M., Fern' andez, J. R., \& Caralt, J. S. (2008). The impact of heritage tourism on an urban economy: The case of Granada and the Alhambra. Tourism Economics, 14(2), 361-376.

World Tourism Organization. (2018). Tourism and culture synergies. Madrid: UNWTO.

Wu, T.-C. E., Xie, P. F., \& Tsai, M.-C. (2015). Perceptions of attractiveness for salt heritage tourism: A tourist perspective. Tourism Management, 51, 201-209. 